УДК 336.647/648

JEL Classification G17

\title{
СОВЕРШЕНСТВОВАНИЕ МЕХАНИЗМА ВОССТАНОВЛЕНИЯ ПЛАТЕЖЕСПОСОБНОСТИ КОМПАНИИ С УЧАСТИЕМ ТРАНСНАЦИОНАЛЬНОГО КАПИТАЛА В ХОДЕ ПРОЦЕДУР НЕСОСТОЯТЕЛЬНОСТИ
}

\author{
Шапошников Владислав Александрович \\ д-р. экон. наук, доцент, профессор кафедры экономики, \\ менеджмента и маркетинга \\ ФГАОУ ВО «Российский государственный \\ профессионально-педагогический университет»
}

Нечкин Олег Сергеевич соискатель ученой степени кандидата экономических наук

Аннотация: цель исследования в данной статье - обоснование и разработка методических рекомендаций по совершенствованию механизма и применения материальной консолидации при восстановлении платежеспособности компаний с участием транснационального капитала. Авторами предложена методика комплексной оценки несостоятельности, которая позволяет оценить реальные возможности восстановления платежеспособности консолидированной группы и компании с участием транснационального капитала, исключая ликвидационную направленность.

Статья предназначена для обучающихся на экономических специальностях, аспирантов, преподавателей, исследователей, практиков и представителей органов государственной власти для регулирования антикризисных мер по восстановлению платёжеспособности компаний с участием транснационального капитала.

Ключевые слова: трансграничное банкротство, анализ финансового состояния, совокупная консолидация, принудительная консолидация СОМIстандарт, финансовое оздоровление, трансграничный капитал. 


\title{
IMPROVEMENT OF THE COMPANY 'S CAPACITY TO PAY WITH THE PARTICIPATION OF TRANSNATIONAL CAPITAL IN INSOLVENCY PROCEEDINGS
}

\author{
Vladislav A. Shaposhnikov, \\ Oleg S. Nechkin
}

\begin{abstract}
: the purpose of the study in this article is to substantiate and develop methodological recommendations for improving the mechanism and application of material consolidation in restoring the solvency of companies with the participation of transnational capital. The authors proposed a methodology for a comprehensive assessment of insolvency, which allows assessing the real possibilities of restoring the solvency of the consolidated group and the company with the participation of transnational capital, excluding the liquidation focus.

The article is intended for students in economic specialties, graduate students, teachers, researchers, practitioners and representatives of state authorities to regulate anti-crisis measures to restore the solvency of companies with the participation of transnational capital.
\end{abstract}

Key words: cross-border bankruptcy, insolvency, financial analysis, aggregate consolidation, COMI - standard, financial recovery, cross-border capital.

\section{Теоретическая часть}

Институт банкротства является неотъемлемой частью рыночной экономики. Процессы ликвидации и реорганизации компаний с участием транснационального капитала во многих странах мира в соответствие с данными, опубликованными в открытых источниках, неуклонно растут и, по мере расширения международных экономических отношений и глобализации экономики, восстановление платёжеспособности в ходе процедур банкротства приобретает ключевое значение.

Несостоятельность компаний с участием транснационального капитала стимулирует совершенствование и разработку новых механизмов восстановления платежеспособности в рамках процедуры несостоятельности (банкротства), выходящей за пределы одного государства. Особое место в проблематике оценки банкротства компаний с участием транснационального капитала и реализации системы антикризисного управления занимает выбор подхода при проведении анализа финансового состояния. Существенные различия в раскрытии показателей финансовой отчетности по российским правилам и, в соответствии $\mathrm{c}$ Международными Стандартами Финансовой Отчетности (далее по тексту - 
МСФО), отражаются на результатах оценки несостоятельности, а достоверное определение движения и выявление активов должника с учетом стран базирования и места его фактического нахождения с целью формирования конкурсной массы, требует иного подхода при управлении и санации должника. [Банеева Г.А. Самедова Д.М., 2016]

Компания с участием транснационального капитала - часть группы лиц в единой системе управления, основанная на участии в уставных (складочных, акционерных и совместных) капиталах и договорных отношениях, независимо от юридической формы, имеющая деловые интересы в двух и более принимающих странах, деятельность которой регламентируется законами соответствующих национальных государств.

В настоящее время применяют три способа создания юридического лица с участием транснационального капитала:

а) создается новое предприятие с максимальным участием иностранного юридического лица (регистрация такого предприятия проводится в соответствии с законодательством принимающей страны) или приобретается контроль в уже существующей организации (в том силе в российской) и юридическое лицо получает статус коммерческой организации с иностранными инвестициями (смешанной);

б) оформляется долевое участие в российской коммерческой организации (не менее 10\% уставного капитала);

в) открывается филиал или представительство иностранного юридического лица.

В Российской Федерации сложились определенные формы объединений юридических лиц с участием транснационального капитала, которые состоят из формально независимых по отношению к друг другу юридических лиц, однако связанные контролем и влиянием, поэтому безусловно рассматриваются как единые субъекты. Документом, подтверждающим влияние компаний с участием транснационального капитала на экономику Российской Федерации является Федеральный закон от 29.04.2008г. № 57-Ф3 «О порядке осуществления иностранных инвестиций в хозяйственные общества, имеющие стратегическое значение для обеспечения обороны страны и безопасности государства».

Показатели деятельности организаций с участием трансграничного капитала по видам экономической деятельности (согласно данным государственной статистики) представлены в табл. 1. 
Таблица 1

Показатели деятельности организаций с участием трансграничного капитала по видам экономической деятельности

\begin{tabular}{|c|c|c|c|}
\hline Виды деятельности & $\begin{array}{c}\text { Число организаций с } \\
\text { участием } \\
\text { трансграничного } \\
\text { капитала }\end{array}$ & $\begin{array}{c}\text { Среднесписочная } \\
\text { численность } \\
\text { работников, } \\
\text { тыс. чел. }\end{array}$ & $\begin{array}{c}\text { Оборот } \\
\text { организаций, } \\
\text { млрд. руб. }\end{array}$ \\
\hline Сельское хозяйство & 702 & 55,8 & 171,1 \\
\hline Рыболовство, рыбоводство & 39 & 3,3 & 23,1 \\
\hline $\begin{array}{ll}\text { Добыча } & \text { полезных } \\
\text { ископаемых }\end{array}$ & 442 & 216,8 & 3420,6 \\
\hline $\begin{array}{l}\text { Обрабатывающие } \\
\text { производства }\end{array}$ & 4060 & 1332,2 & 15304 \\
\hline $\begin{array}{l}\text { Производство } \\
\text { электроэнергии }\end{array}$ & 271 & 323,3 & 2511 \\
\hline Строительство & 1521 & 113,3 & 592 \\
\hline $\begin{array}{l}\text { Оптовая } \quad \text { и } \quad \text { розничная } \\
\text { торговля }\end{array}$ & 8187 & 740,5 & 15991,1 \\
\hline Гостиницы и рестораны & 707 & 64,7 & 183,3 \\
\hline Транспорт и связь & 1742 & 323,8 & 3533,4 \\
\hline Операции с недвижимостью & 5238 & 228,4 & 1397,3 \\
\hline Образование & 45 & 2,1 & 2,2 \\
\hline $\begin{array}{l}\text { Здравоохранение } \text { и } \\
\text { услуги }\end{array}$ & 240 & 23,6 & 49,6 \\
\hline Прочее & 324 & 17,1 & 90 \\
\hline ИТОГО & 23518 & 3444,9 & 43268,8 \\
\hline
\end{tabular}

Соотношение трансграничного капитала к ВВП и расходной части бюджета Российской Федерации (\%), представлено на рис. 1.

Трансграничный капитал

Расходная часть бюджета РФ

ВВП

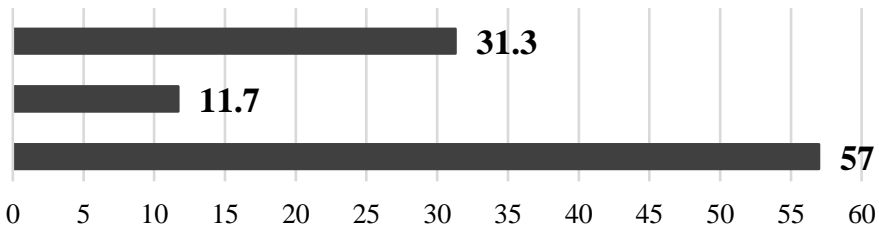

$\begin{array}{lllllllllllll}0 & 5 & 10 & 15 & 20 & 25 & 30 & 35 & 40 & 45 & 50 & 55 & 60\end{array}$

\section{Рис. 1. Соотношение трансграничного капитала к ВВП и расходной части бюджета Российской Федерации (\%).}

Контроль для идентификации участников группы юридических лиц 
определяются в соответствии с установленными МСФО, признаваемыми на территории Российской Федерации, однако не учитываемые при проведении анализа финансового состояния в ходе процедур банкротства.

\section{Применение материальной консолидации в качестве инструмента} восстановления платежеспособности при использовании критерия

\section{инкорпорации (домицилия) контролирующих лиц}

Мировая практика антикризисного управления утвердила критерий международной подсудности - центр основных интересов должника (далее по тесту СОМІ-стандарт) в основе которого лежит принцип территориальности. COMI-стандарт основан на постулате, что центр интересов должника, может быть смещен в правовую систему иного государства при совокупности двух исчерпывающих условий: если место осуществления управления интересами и деловой активности должника находится в отличном от места инкорпорации, государстве; если конкурсным кредиторам должника это было очевидно [2].

Критерии возбуждения дел о банкротстве представлены на рис. 2.

Территориальность расположения основного и вторичного производства по делу о трансграничном банкротстве

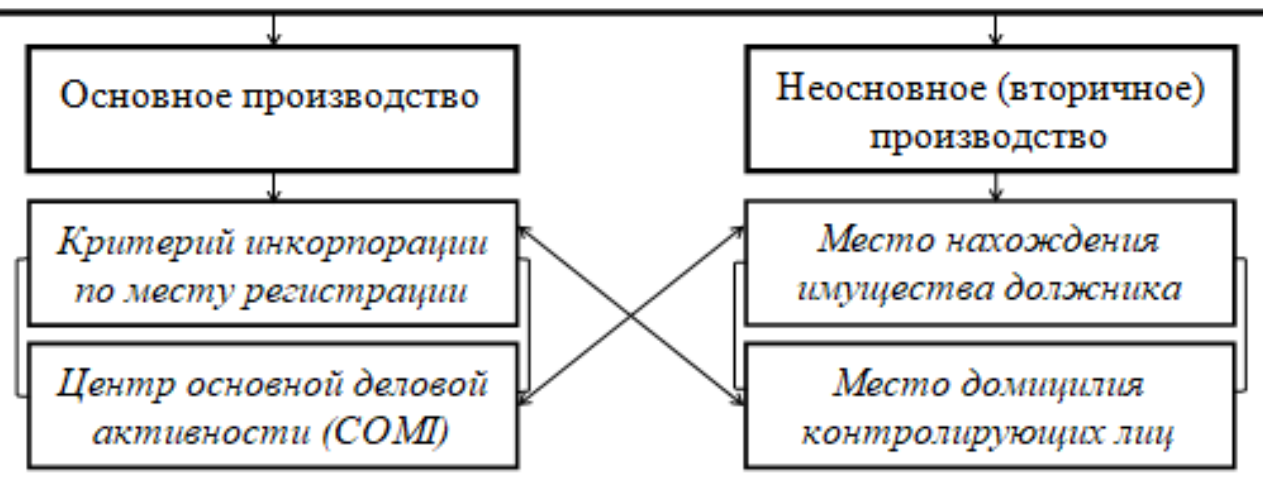

\section{Рис. 2. Критерии возбуждения основного и вторичного производства по делу о банкротстве.}

Карта государств, где территориальность позволяет возбуждение основного и неосновного (вторичного) производства по делу о трансграничном банкротстве представлена на рис. 3. 


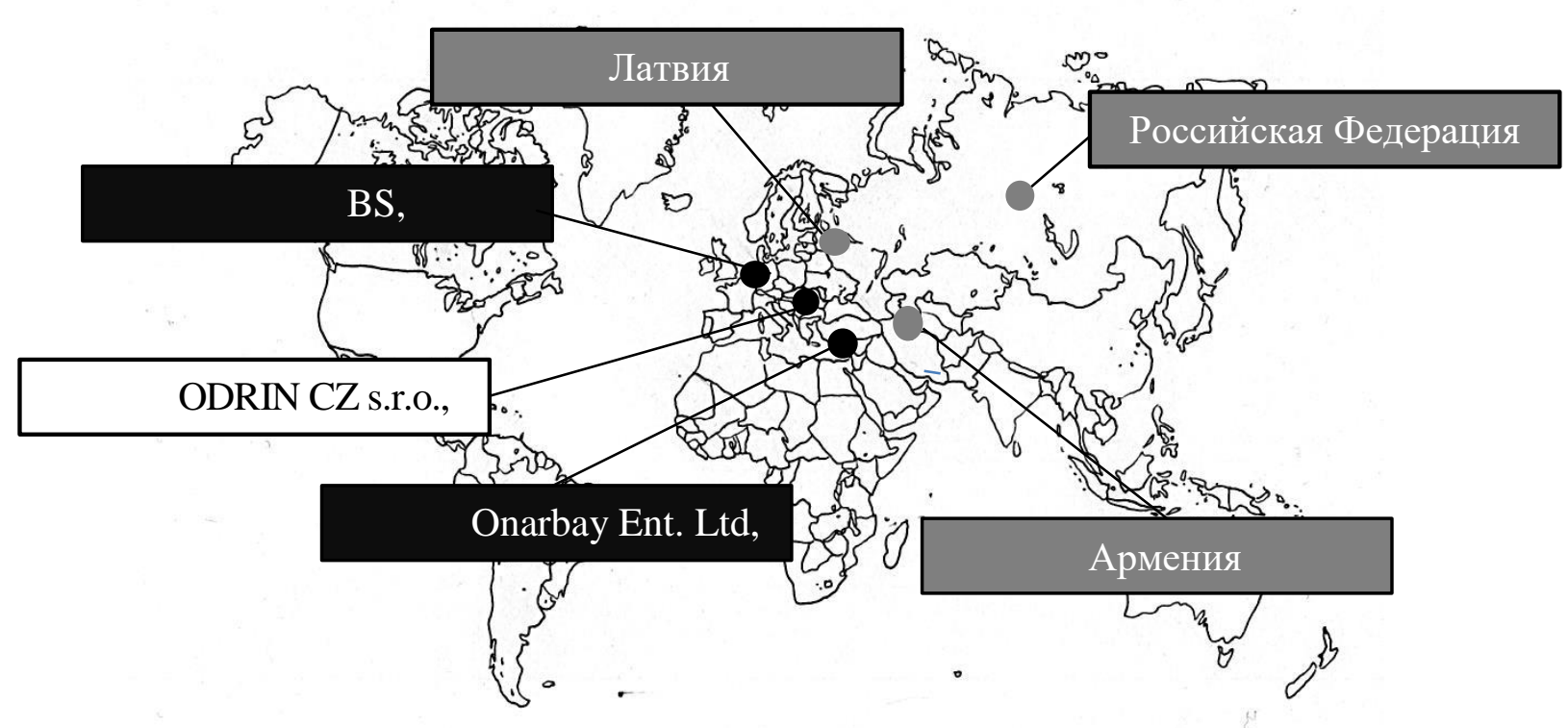

\section{Рис. 3. Карта государств, реализующих принцип территориальности}

Общий механизм восстановления платежеспособности компании и формирования имущества для его реализации с учетом рекомендаций представлен на рис. 4. 


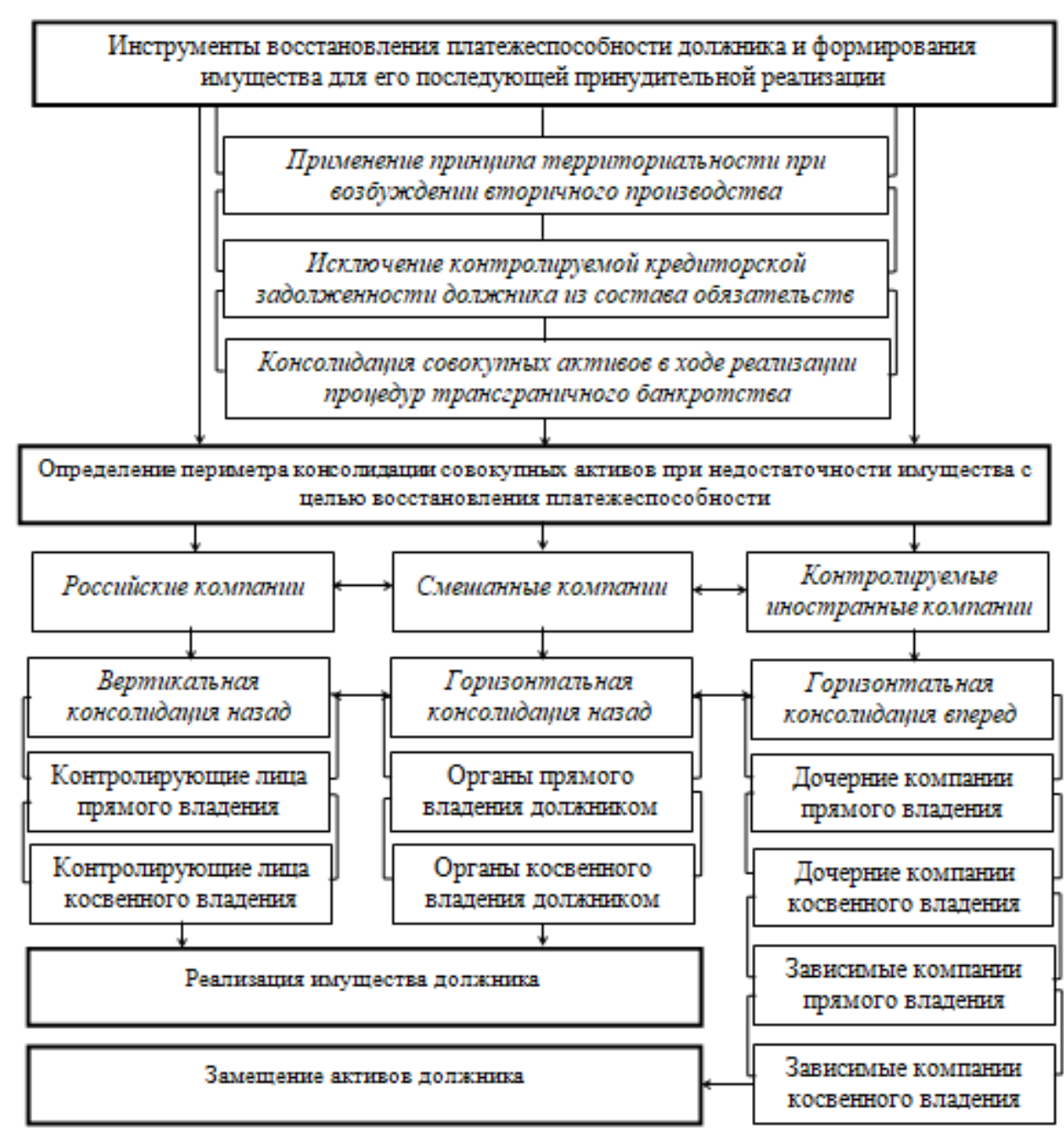

\title{
Рис. 4. Общий механизм восстановления платежеспособности компании с участием транснационального капитала с учетом рекомендаций
}

\author{
Мобильность применяемого СОМІ-стандарта сформировала в
} международном частном праве отрицательную практику за счет злоупотребления со стороны контролирующих лиц в виде манипуляции юрисдикциями и выбор наиболее выгодного государства в качестве страны проведения банкротства в ущерб интересам кредиторам. Для государств, процессуальные вопросы определения международной подсудности регулируются внутренними национальными нормами, которые не учитывают особенности трансграничного банкротства и экономической модели хозяйствующего субъекта, что препятствует восстановлению платежеспособности [5].

Используя принцип инкорпорации контролирующих лиц в качестве альтернативы в ходе процедуры трансграничной несостоятельности, формируются 
условия для консолидации активов как должника, так и контролирующей компании $[4]$.

Методика комплексного анализа финансового состояния компании с участием транснационального капитала в ходе процедур несостоятельности

В основу комплексного анализа финансового состояния положено:

- метод выявления учетных несоответствий;

- метод сопоставления взаимоувязанных показателей в сопряженных финансовых документах;

- метод специальных расчетных и корректирующих показателей;

- совокупный анализ коэффициентов финансово-хозяйственной деятельности на основе финансовой отчетности составленной в соответствии с РПБУ и консолидированной финансовой отчетностью.

Совокупность применяемых методов позволяет проводить расчет уровня существенности - базовый показатель, который указывает на размер искажений финансовой отчетности, не является постоянной величиной и в каждом случае рассчитывается отдельно [6].

Так, в соответствии с действующими стандартами на территории РФ предлагаемая величина допустимой погрешности бухгалтерской отчетности для исчисления уровня существенности (УСС) составляет 5\% от балансовой прибыли предприятия, 2\% от валового объема реализации без НДС, 2\% от валюты баланса, $10 \%$ от собственного капитала, 2\% от общих затрат предприятия.

Расчет уровня существенности проводится по следующей формуле:

$$
\mathrm{yCC}=\sum \frac{3 \Pi}{\mathrm{x}}
$$

где,

УСС - уровень существенности;

ЗП - значение базового показателя;

$\mathrm{X}$ - количество используемых показателей для расчета;

Расчет уровня существенности по статьям баланса представлен в следующей формуле:

$$
\operatorname{yCC}_{i}=\operatorname{yCC} \frac{\mathrm{T}_{i}^{d}+\mathrm{T}_{i}^{k}+\mathrm{C}_{i}}{\mathrm{~T}+\mathrm{C}}
$$

где,

УСС $_{i}$ - уровень существенности по $i$ статье баланса;

$\mathrm{T}_{i}^{d}$ - дебетовый оборот по $i$ статье баланса;

$\mathrm{T}_{i}^{k}$ - кредитовый оборот по $i$ статье баланса;

$\mathrm{T}$ - оборот по дебету или кредиту за отчетный период по всем счетам; 
$\mathrm{C}_{i}$ - сальдо по $i$ статье баланса.

Основные коэффициенты финансово-хозяйственной деятельности для проведения анализа финансового состояния по данным РПБУ и МСФО на примере консолидированной группы UPESP, представлены в табл. 2.

Таблица 2

Основные коэффициенты финансово-хозяйственной деятельности для проведения анализа финансового состояния по данным РПБУ и МСФО

\begin{tabular}{|l|c|c|c|c|}
\hline \multirow{2}{*}{ Наименование показателя } & \multicolumn{2}{|c|}{$\begin{array}{c}\text { Значение на } \\
\text { предшествующй период }\end{array}$} & \multicolumn{2}{|c|}{$\begin{array}{r}\text { Значение на отчетную } \\
\text { дату }\end{array}$} \\
\cline { 2 - 5 } & РПБУ & МСФО & РПБУ & МСФО \\
\hline $\begin{array}{l}\text { Коэффициент абсолютной } \\
\text { ликвидности }\end{array}$ & 0,81 & 0,07 & 0,16 & 0,15 \\
\hline $\begin{array}{l}\text { Степень платёжеспособности по } \\
\text { текущим обязательствам }\end{array}$ & 3,53 & 5,52 & 4,93 & 4,94 \\
\hline Коэффициент текущей ликвидности & 2,14 & 1,17 & 1,90 & 1,23 \\
\hline $\begin{array}{l}\text { Коэффициент обеспеченности } \\
\text { обязательств }\end{array}$ & 3,21 & 1,55 & 1,91 & 1,81 \\
\hline $\begin{array}{l}\text { Коэффициент обеспеченности } \\
\text { собственными оборотными средствами }\end{array}$ & $-0,82$ & $-1,31$ & $-0,34$ & $-1,0$ \\
\hline Коэффициент автономии & 0,44 & 0,36 & 0,48 & 0,45 \\
\hline $\begin{array}{l}\text { Доля просроченной кредиторской } \\
\text { задолженности в пассивах }\end{array}$ & 0,59 & 0,64 & 0,45 & 0,55 \\
\hline $\begin{array}{l}\text { Коэффициент отношения дебиторской } \\
\text { задолженности к совокупным активам }\end{array}$ & 0,09 & 0,07 & 0,09 & 0,08 \\
\hline Рентабельность совокупных активов & 0,08 & 0,06 & 0,07 & 0,09 \\
\hline Норма чистой прибыли & 0,10 & 0,08 & 0,13 & 0,13 \\
\hline
\end{tabular}

Сравнение финансовых показателей по форме РПБУ и МСФО указывает на преимущество РПБУ в части позитивной динамики активных статей финансовой отчетности. Однако, динамика изменения коэффициентов, рассчитываемых в ходе несостоятельности, демонстрирует ухудшение шести аналитических коэффициентов. Отчетность МСФО (при наличии низких показателей финансовой 
устойчивости) содержит ухудшение только трех коэффициентов, что является показательным фактом при выявлении признаков преднамеренного банкротства и влияет на анализ и оценку реальных возможностей восстановления платежеспособности компании с участием транснационального капитала.

1. По итогам коэффициентного анализа финансово-хозяйственной деятельности на основании РПБУ, можно сделать следующие выводы: наиболее ликвидных активов недостаточно для своевременного погашения обязательств; отрицательная динамика показателей свидетельствует о низкой эффективности деятельности; выявлено снижение уровня платежеспособности.

Обобщая результаты анализа коэффициентов (показателей) финансовохозяйственной деятельности можно сделать заключение о том, что предприятие неплатежеспособно, наиболее ликвидных активов может быть недостаточно для своевременного погашения обязательств; активы сформированы за счет заемного капитала; восстановление платежсеспособности в порядке и сроки, установленные Ф3 № 127 «О несостоятельности (банкротстве)», невозможнно.

2. По итогам коэффициентного анализа финансово-хозяйственной деятельности составленного на основании консолидированной отчетности можно сделать следующие выводы: наиболее ликвидных активов недостаточно для своевременного погашения обязательств; рост уровня платежеспособности и ликвидности; повышение уровня обеспеченности.

Обобщая результаты анализа коэффициентов (показателей) финансовохозяйственной деятельности можно сделать следующее заключение. Предприятие неплатежеспособно, наиболее ликвидных активов может быть недостаточно для своевременного погашения обязательств; активы сформированы за счет заемного капитала; динамика роста показателей ликвидности и обеспеченности свидетельствуют о возможности восстановления платежеспособности в порядке и сроки, установленные Федеральным законом № 127 «О несостоятельности (банкротстве)».

Взаимоисключающие выводы являются доказательством необходимости сопоставления показателей отчетности для принятия решения о возможности восстановления платежеспособности за счет скрытых резервов, не отраженных в финансовой отчетности, составленной по РПБУ.

Сопоставление расчетных данных при материальной консолидации контролируемых иностранных компаний

Основной идеей материальной консолидации является объединение имущества и имущественных прав и обязательств компании с участием 153 
транснационального капитала, состоящей из множества фирм, для целей рассмотрения дела о несостоятельности. В настоящее время материальная консолидация как инструмент восстановления платежеспособности несостоятельных компаний широко применяется в США, Новой Зеландии и Великобритании. Так, в деле о несостоятельности компании Exchange Securities \& Commodities Ltd антикризисный управляющий предложил погасить кредиторскую задолженность путем объединения всех активов, а затем распределив полученные доходы среди кредиторов, удовлетворив их требования [7].

Примером принудительной консолидации совокупных активов может выступать дело KPNQuest N.V. - консолидированной группы компаний на территории Европейского Союза. В отношении материнской компании было возбуждено дело о банкротстве, и были возбуждены обособленные дела о несостоятельности каждой из дочерней компании, входящих в группу. По итогам процедуры конкурсного производства активы дочерней компании, были реализованы по отдельности, что существенно снизило их стоимость и сделало невозможным реорганизацию и сохранение имущественного комплекса корпорации за счет совокупной консолидации. Прогнозный баланс при процедуре консолидации совокупных активов должника и активов контролирующего лица представлен в табл. 3.

Таблица 3

\section{Прогнозный баланс при консолидации совокупных активов должника и} активов контролирующего лица прямого владения, в млн. руб.

\begin{tabular}{|l|c|c|c|}
\hline \multicolumn{4}{|c|}{ Бухгалтерский баланс } \\
\hline & $\begin{array}{c}\text { АКТИчение на } \\
\text { отчетную дату }\end{array}$ & $\begin{array}{c}\text { Прогноз по } \\
\text { итогам } \\
\text { консолидации }\end{array}$ & Отклонение \\
\hline Внеоборотные активы & 475,2 & 694,8 & 219,6 \\
\hline Нематериальные активы & 0,1 & 5491,2 & 5 491,2 \\
\hline Результаты исследований & 1,2 & 1,2 & - \\
\hline $\begin{array}{l}\text { Нематериальные поисковые } \\
\text { активы }\end{array}$ & - & - & - \\
\hline $\begin{array}{l}\text { Поисковые материальные } \\
\text { активы }\end{array}$ & - & - & - \\
\hline Основные средства & 311,7 & 311,7 & - \\
\hline Доходные вложения & 9,1 & 9,1 & 43606,2 \\
\hline Финансовые вложения & 128,4 & 43735,6 & \\
\hline
\end{tabular}




\begin{tabular}{|c|c|c|c|}
\hline \multicolumn{4}{|c|}{ Бухгалтерский баланс } \\
\hline Налоговые активы & - & 2997 & 2997 \\
\hline $\begin{array}{l}\text { Прочие } \quad \text { внеоборотные } \\
\text { активы }\end{array}$ & 24,8 & 24,8 & - \\
\hline Оборотные активы & 74,3 & 74,3 & - \\
\hline Запасы & 5,1 & 5,1 & - \\
\hline НДС & 0,6 & 0,6 & - \\
\hline Дебиторская задолженность & 50,2 & 7870,4 & 7820,2 \\
\hline Денежные средства & 15,6 & 555,1 & 540,5 \\
\hline Прочие оборотные активы & 0,6 & 6545,1 & 6539 \\
\hline Баланс & 549,5 & 68315,1 & 67766 \\
\hline \multicolumn{4}{|c|}{ ПАССИВ } \\
\hline Капитал и резервы & 262,5 & 262,5 & - \\
\hline Уставный капитал & - & - & - \\
\hline $\begin{array}{l}\text { Собственные выкупленные } \\
\text { акции }\end{array}$ & $(23,3)$ & $(23,3)$ & \\
\hline Переоценка & 3,5 & 3,5 & - \\
\hline Добавочный капитал & 129,9 & 129,9 & - \\
\hline Резервный капитал & - & 67193,1 & 67193,1 \\
\hline Нераспределенная прибыль & 152,3 & 152,3 & - \\
\hline $\begin{array}{l}\text { Долгосрочные } \\
\text { обязательства }\end{array}$ & 167,6 & 167,6 & - \\
\hline Заемные средства & 138,9 & 138,9 & - \\
\hline Налоговые обязательства & 26 & 26 & - \\
\hline Оценочные обязательства & 0,5 & 0,5 & - \\
\hline Прочие обязательства & 2,2 & 2,2 & - \\
\hline $\begin{array}{l}\text { Краткосрочные } \\
\text { обязательства }\end{array}$ & 119,3 & 119,3 & - \\
\hline Заемные средства & 53,7 & 53,7 & - \\
\hline $\begin{array}{l}\text { Кредиторская } \\
\text { задолженность }\end{array}$ & 54,4 & 54,4 & - \\
\hline Доходы будущих периодов & 0,5 & 0,5 & - \\
\hline Оценочные обязательства & 10,7 & 10,7 & - \\
\hline Прочие обязательства & - & - & - \\
\hline Баланс & 549,5 & 68315,1 & 67765,6 \\
\hline
\end{tabular}

Прогнозный баланс при консолидации совокупных активов должника и активов дочерних компаний прямого владения представлен в табл. 4 
Таблица 4

Прогнозный баланс при консолидации совокупных активов должника и активов дочерних компаний прямого владения, в млн. руб.

\begin{tabular}{|c|c|c|c|}
\hline \multicolumn{4}{|c|}{ Бухгалтерский баланс } \\
\hline \multicolumn{4}{|c|}{ АКТИВ } \\
\hline & $\begin{array}{c}\text { Значение на } \\
\text { отчетную дату }\end{array}$ & $\begin{array}{c}\text { Прогноз по } \\
\text { итогам } \\
\text { консолидации }\end{array}$ & Отклонение \\
\hline Внеоборотные активы & 475,2 & 975 & 499,8 \\
\hline Нематериальные активы & 0,1 & 3,9 & 3,8 \\
\hline Результаты исследований & 1,2 & 327,9 & 326,7 \\
\hline $\begin{array}{l}\text { Нематериальные поисковые } \\
\text { активы }\end{array}$ & - & - & - \\
\hline $\begin{array}{l}\text { Поисковые } \\
\text { активы }\end{array}$ & - & - & - \\
\hline Основные средства & 311,7 & 311,7 & - \\
\hline Доходные вложения & 9,1 & 30761,5 & 30752,4 \\
\hline Финансовые вложения & 128,4 & 2334,2 & 2205,8 \\
\hline Налоговые активы & - & 29721,3 & 29721,3 \\
\hline $\begin{array}{l}\text { Прочие } \\
\text { активы }\end{array}$ & 24,8 & 125,8 & 101 \\
\hline Оборотные активы & 74,3 & 574,1 & 499,8 \\
\hline Запасы & 5,1 & 150,9 & 145,8 \\
\hline НДС & 0,6 & 1,2 & 0,6 \\
\hline Дебиторская задолженность & 50,2 & 706156,3 & 705706,1 \\
\hline Финансовые вложения & 2,3 & 2,3 & - \\
\hline Денежные средства & 15,6 & 23,5 & 7,9 \\
\hline Прочие оборотные активы & 0,6 & 0,7 & 0,1 \\
\hline Баланс & 549,5 & 771470,3 & 770920,8 \\
\hline \multicolumn{4}{|c|}{ ПАССИВ } \\
\hline Капитал и резервы & 262,5 & 262,5 & - \\
\hline Уставный капитал & - & - & - \\
\hline $\begin{array}{l}\text { Собственные } \text { выкупленные } \\
\text { акции }\end{array}$ & $(23,3)$ & $(23,3)$ & - \\
\hline Переоценка & 3,5 & 3,5 & - \\
\hline Добавочный капитал & 129,9 & 129,9 & - \\
\hline Резервный капитал & - & 770587,5 & 770587,5 \\
\hline Нераспределенная прибыль & 152,3 & 152,3 & - \\
\hline $\begin{array}{l}\text { Долгосрочные } \\
\text { обязательства }\end{array}$ & 167,6 & 167,6 & - \\
\hline Заемные средства & 138,9 & 138,9 & - \\
\hline
\end{tabular}




\begin{tabular}{|l|c|c|c|}
\hline \hline \multicolumn{3}{|c|}{ Бухгалтерский баланс } \\
\hline Налоговые обязательства & 26 & 26 & - \\
\hline Оценочные обязательства & 0,5 & 0,5 & - \\
\hline Прочие обязательства & 2,2 & 2,2 & - \\
\hline $\begin{array}{l}\text { Краткосрочные } \\
\text { обязательства }\end{array}$ & 119,3 & 119,3 & - \\
\hline Заемные средства & 53,7 & 53,7 & - \\
\hline $\begin{array}{l}\text { Кредиторская } \\
\text { задолженность }\end{array}$ & 54,4 & 54,4 & - \\
\hline Доходы будущих периодов & 0,5 & 0,5 & - \\
\hline Оценочные обязательства & 10,7 & 10,7 & 770920,8 \\
\hline Прочие обязательства & - & - & \\
\hline Баланс & 549,5 & 771470,3 & \\
\hline
\end{tabular}

Сводные данные о наиболее оборачиваемых активах дочерних компаний прямого владения представлены в табл. 5.

Таблица 5

Сводные данные о наиболее оборачиваемых активах дочерних компаний прямого владения, млн. руб.

\begin{tabular}{|l|c|}
\hline \multicolumn{1}{|c|}{ Сводные данные } & Млн. руб. \\
\hline Активы & 771470,3 \\
\hline Дебиторская задолженность & 706156,3 \\
\hline Финансовые вложения & 2334,2 \\
\hline Денежные средства & 23,5 \\
\hline
\end{tabular}

Представленные инструменты обеспечивают рост ликвидности и обеспеченности должника за счет принудительной консолидации совокупных активов, способствуют увеличению конкурсной массы, способствуют восстановлению платёжеспособности должника, что является ключевой целью при повышении эффективности антикризисного управления в ходе процедур несостоятельности.

\section{Заключение}

Для характеристики финансового состояния оказалось принципиально важным, каким образом интерпретируется финансовая отчетность. Выводы по итогам анализа финансового состояния будут существенно различаться, особенно в отношении таких показателей как динамика изменения коэффициентов платёжеспособности, деловой активности и финансовой устойчивости должника. 
Комплексный анализ финансового состояния компании позволяет достоверно оценить причины утраты платёжеспособности и реальные возможности восстановления платежеспособности компании с участием транснационального капитала и/или консолидированной группы, что обеспечит проведение санации, исключая ликвидационную направленность.

Применение материальной консолидации позволит в короткий срок определить состав совокупных активов принадлежащих должнику и его корпоративной группе, а также периметр его принудительной консолидации для включения в конкурную массу, что снизит срок проведения процедуры конкурного производства и расширит перечень установленных мер направленных на восстановление платёжеспособности, что является ключевой целью при повышении эффективности антикризисного управления в ходе процедур трансграничного банкротства.

\section{Список литературы}

1. Банеева Г.А. Самедова Д.М., Особенности и проблемы применения МСФО в России. Бухгалтерский учет и аудит: прошлое, настоящее и будущее. Сборник научных статей региональной научно-практической конференции: в 2 частях. 2016. С. 131-134. Доступ из справ. - правовой системы «КонсультантПлюс» (Дата обращения: 23.11.2019).

2. Мохова Е.В. Обеспечение "изначальной предсказуемости" при определении "базовой страны должника" в случаях трансграничной несостоятельности юридических лиц // Северокавказский юридический вестник. // [Электр. ресурс] // 2007 №2. Доступ из справ. - правовой системы «Консультант-Плюс» (Дата обращения: 23.11.2019).

3. Мохова Е.В. Центр основных интересов должника при трансграничной несостоятельности: перспективы введения в России новых правовых конструкций // Закон // [Электр. ресурс] // 2012. № 10. Доступ из справ. - правовой системы «Консультант-Плюс» (Дата обращения: 20.11.2019).

4. Орлова О.Е. Новое в законодательстве о контролируемых иностранных компаниях. // Актуальные вопросы бухгалтерского учета и налогообложения // [Электр. ресурс] // 2016. № 4. Доступ из справ. - правовой системы «Консультант-Плюс» (Дата обращения: 25.11.2019).

5. Собина Л.Ю. Признание иностранных банкротств в международном частном праве // Статут // [Электр. ресурс] // 2012. Доступ из справ. - правовой системы «Консультант-Плюс» (Дата обращения: 23.09.2018). 
6. Сунгатуллина Р. Н. Существенность и подходы к определению уровня. Канд. экон. наук, доцент. Бухгалтерский учет, статистика. Экономические науки. 2015. 1(122). С.87.

7. Shaposhnikov V.A. Tkacheva O.N., Mikushina M.M. Nechkin O.S. Problem of imperfection of the procedure of cross - border bankruptcy: theoretical methodological aspect. The European Proceedings of Social \& Behavioural Sciences, 2018. ISSN: 2357-1330. 